\title{
An Analysis of the Role of Management in Nuclear Disasters using Text Mining
}

\author{
Jeremy Paul Novak \\ Southern Cross Business School, Southern Cross University, Australia \\ Email: jeremy.novak@scu.edu.au \\ Yvonne Brunetto \\ Southern Cross Business School, Southern Cross University, Australia \\ Kerry Brown \\ School of Management, Curtin Business School, Curtin University, Australia
}

\begin{abstract}
This study uses text mining as a method of examining the role of management and culture in three disasters in the nuclear energy sector, Three Mile Island nuclear reactor explosion (USA 1979), Chernobyl nuclear plant explosion (Ukraine then USSR 1986) and the Fukushima Daiichi nuclear disaster (Japan 2011). The findings identify the role of management in shaping the quality of the crisis and disaster mitigation and preparedness management process employed by organisations. The implications of the findings are that it is imperative for organisations to develop and employ effective crisis/disaster management practice.
\end{abstract}

Key Words: Crisis, , Mitigation, Manager, Critical Infrastructure Organisation, Disaster Management, Three Mile Island, Fukushima Daiichi, Chernobyl, nuclear disaster

\subsection{Introduction}

The nuclear power sector is one that has been surrounded by controversy primarily because of the ongoing disasters that have occurred such as the Three Mile Island nuclear reactor explosion (USA 1979), Chernobyl nuclear plant explosion (Ukraine then USSR 1986) and the Fukushima Daiichi nuclear disaster (Japan 2011). However, the nuclear power sector in some circles is viewed as a viable alternative to the coal and gas power due to the climate change issues and their carbon outputs concerns. The importance of Engineering Asset Management Organisations (EAMO) or Critical infrastructure Organisations (CIO) including power generation stations, dams, water treatment plants, rail, or hospitals to our society cannot be understated. This is because CIOs deliver essential services require that allow communities to function. In countries like Japan, the nuclear power sector delivers energy for the Japanese to survive hence, effective management is required. As a result the general public are demanding better management of CIOs.

Engineering Asset Management Organisations can be defined as those organisations that are concerned with "the total management of physical, as opposed to financial, assets”. 1, p. 162 Within these organisations employees are imperative because they play a key role in crisis and disaster mitigation and prevention and they are responsible for the maintenance, service, repair and general management of assets (both public and private). The issue is that effective management of employees plays an important role in the prevention, mitigation, (pre phases of the crisis and disaster cycle) during and post (before-duringafter?) crisis/disaster events and very little research has taken place about this issue. . This paper examines official enquiry reports of three disaster events in the nuclear energy sector along with related academic literature. The findings inform the academic literature and practice on the role that managers played within a nuclear disaster situation and has implications for informing the body of knowledge about developing better precrisis/disaster management activities.

\subsection{Crisis/disasters and the Role of Management}

While risk and uncertainty are part of the everyday operating environment for all organisations it has been asserted that human induced crisis has the potential to rival natural disasters both in landscape

Published by Atlantis Press

Copyright: the authors 
and magnitude and will continue to do so into the future unless further research is conducted into the role of the human factor. ${ }^{2-5}$ Moreover, it has been suggested that the best way to manage crises/disasters is to understand the role of management issues in both crisis prevention and post-crisis management. ${ }^{6-8}$ Organisations need evidence based information about how to avert potential crisis/disaster situations. Traditionally general business researchers on crisis/disaster management have focused on problems of growth and financial performance, but have paid little attention to the effect of crises/disasters events and the role of management prior to, during and post disaster situations despite both natural and human catastrophes occurring over time. ${ }^{9,10}$ Pang and Yeo 9, p. ${ }^{83}$ further stated that "By most accounts, crisis preparedness in organizations globally has been appalling”. Similarly Faulkner ${ }^{11}$ asserted that despite the potentially devastating effect of manmade and natural disasters, organisations in general have not properly developed disaster strategies as an integral part of their business plans. Other authors have suggested that this is predominantly true, as major crises/disaster situations have been contributed to human errors along with unresponsive culture, bad planning, dishonest behaviour, material failure, the lack of good training and development and management failures. $^{6,12-14}$

According to the previously published data, the energy sector has been recognised as one of the main contributors to man-made disasters since the 1970 's. ${ }^{15-18}$ In their review of accidents in this sector, Sovacool ${ }^{17}$ said that there has been 279 major energy accidents in the coal, oil, natural gas, hydroelectric, renewable, and nuclear sectors resulting in approximately 200,000 deaths and \$41 billion in damages from 1907 to 2007. These statistics did not take into consideration the Fukushima Daiichi nuclear disaster (Japan 2011) or other social and economic impacts in those countries that have experienced a crisis or disaster event. These authors further highlighted that there was a combination of technical complexity, speed, tight coupling with substantial human fallibility contributing to the unexpected failure of large-scale energy assets. Therefore, the overall understanding of the role of management within this context of EAMO or CIO is limited and calls for further research have been made. ${ }^{19,20}$ In general Nuclear energy and other asset accidents are an important concern for analysts, policymakers and governments. Although, there is a well-established literature on analysing energy accidents, more research is needed in the area of human factors in organisations, which will inform policymakers so that society's safety is guaranteed. ${ }^{21-23}$
Recent research identifies evidence linking that the management at all levels is critical in communicating and maintaining an organisation's purpose, values, vision and performance, which is important in achieving safety outcomes. ${ }^{24-31}$ It is further argued that good management can curtail or assist in avoiding a crises/disaster situation to some degree, by incorporating strategies for coping with the unexpected event over which the organisation has little control. ${ }^{11}$ However, a review of the EAMO literature finds that there has been little attention or research about the impact of the human element in EAMO. ${ }^{1,32,33}$ Moreover, there has been very limited research into the role management plays in crisis/disaster management activities ${ }^{20,34}$ as research in EAMO has been traditionally focused on the management of physical assets or hardware. $^{32}$

\subsection{Organisational culture}

Organisational culture can be defined as "a system of shared beliefs and values that guides behaviour." Similarly Wood et. al ${ }^{25}$ p. 325 and Hofstede ${ }^{41}$ p. 262 defined organisational culture as the "collective programming of the mind" where a safety culture of an organisation is “... its set of beliefs, norms and practices relevant to the organization and the safety of its operations. Human error along with an unresponsive culture, bad planning, dishonest behaviour, material failure, the lack of good training and development and management failures are all factor affecting safety outcomes. It is management's role to ensure that employees received adequate training so that human errors are reduced. ${ }^{6,12-14,36}$ For these reasons it is important that employees are supported by a strong and competent management team that understands the value of building a competent employee based. ${ }^{37}$ Management practices in an organisation have been identified as the "strongest influences on the cultural norms of employees" because it affects employee's expectation and responsibilities about the role of training and innovative behaviour in the workplace”. ${ }^{38, \text { p. } 16}$ Moreover, management practices have been linked to the existence of a strong safety culture. $^{39}$ Despite the acknowledgement that organisational culture and safety culture are important there is limited consensus about the definition of organisational culture, and its classification. $^{32}$ However, the general consensus seems that organisational culture consists of shared values, practices and beliefs amongst actors within side an organisation. ${ }^{25,40,41}$

Organisational culture and safety culture are important because it can have a great effect on the safety practices, and employee attitudes toward , innovative behaviour, products and processes, 
product and service quality and the overall performance of an organisation. ${ }^{20,} 40,42$ Strong cultures have a higher chance of implementing organisational policies and objectives, especially safety goals, ${ }^{40,} 43$ all of which are important for strengthening employee ties to one another, improving commitment as a collective, developing employee understanding of organisational requirements, all of which can increase organisational performance. $^{44}$ Perhaps most importantly organisations with a strong organisational and safety culture have a better chance of mitigating crisis/disaster events

While a robust discussion exists in the general academic literature there appears very limited research into the role of management on forming a strong organizational culture and safety culture within EAMO. For example research by El-Baz and El-Sayegh ${ }^{45}$ in the United Arab Emirates found that the understanding and recognition of the importance of organisational culture was very limited within their participants. Similarly Zuashkiani et al. ${ }^{20}$, who were the first to develop an effective capability framework for EAMO, identified that traditionally there has been a culture of reactive maintenance, and a dominate culture of "fire-fighting" within EAMO along with inconsistent direction from the management about the job priorities have led to poor safety outcomes for the organisation. However, very little research has examined of the role of management and organisational culture in EAMO except for authors such as Brunetto and Xerri ${ }^{32}$ and Lloyd. ${ }^{33}$

\subsection{Methods and Document Selection}

For this research, a review of documents of three $(\mathrm{N}=3)$ major crisis/disaster events in the nuclear power generation sector was conducted; Three Mile Island nuclear reactor explosion (USA, 1979), Chernobyl nuclear plant explosion (Ukraine then the USSR, 1986), and the Fukushima Daiichi nuclear disaster (Japan, 2011). The first case under investigation occurred on March 28, 1979 at the Three Mile Island nuclear reactor in Pennsylvania. This disaster caused zero deaths however, due to a faulty valve and the stopping of the primary feedwater pumps at TMI Unit 2; containing 36,816 fuel rods, ${ }^{46}$ this prevented the large steam generators at the reactor site from removing necessary exhaust heat. The flow on effect was the steam turbines and reactor automatically shutting down where there was an escape of contaminated coolant water out of the open faulty valve, this caused the core of the reactor to overheat resulting in the partial core meltdown of the nuclear reactor. ${ }^{46-48}$ The Three Mile Island nuclear disaster resulted in excess of $\$ 2.4$ billion in property damages ${ }^{17}$ and major social impact to the local and wider community as public fear and distrust increased and there was a backlash towards the nuclear industry more widely. ${ }^{48}$

Perhaps the most well-known nuclear disaster in global history is the Chernobyl nuclear plant explosion. On April 25th 1986 Chernobyl nuclear plant exploded killing at least 4100 people and damaging almost $\$ 7$ billion of property. The disaster resulted in evacuation of thousands of people from nearby towns and the deployment of a toxic cloud that made its way over Europe. ${ }^{17,49}$ The final disaster under investigation was Fukushima Daiichi Nuclear Power Plant. On March 11, 2011, the Great East Japan Earthquake triggered a tsunami where it caused flooding of a pit housing an emergency diesel generator. This flooding destroyed the emergency diesel generators and resulted in coolant not reaching the reactor as a result an extremely severe explosion occurred, resulting in an estimated 200,000 people been evacuated in a $20 \mathrm{~km}$ radius of the plant. ${ }^{50}$

The authors identified a large and varied body of literature that discussed these three disasters. The literature ranged from the grey literature such as; blogs, webpages, social media, newspaper articles, industry magazines and so on, through to the academic literature and official reports into the disaster itself. For the purpose of this paper two literature sets were chosen, the first set was the original official enquiries reports into the three nuclear disasters ( $\mathrm{N}=5$ ), and to the second set was academic peered reviewed Journal articles from the management perspective. After the two literature sets were chosen, subsequent cross checking using a manual screening technique to determine the relevance of the documents was conducted. Overall 174 academic peered reviewed documents identified and reviewed. From this set 95 documents were found to be relevant and were included $(\mathrm{N}=95)$ in the analysis.

The peered reviewed Journal articles were sourced from various databases including but not limited to:

- Business Source Premier

- Emerald

- Factiva

- ProQuest

- ScienceDirect

- Web of Science - all databases

- Ulrichsweb

After the filtering of the relevant documents a data analysis was conducted by utilising Leximancer software. Leximancer is an assisted qualitative data analysis software package that uses proximity values for text mining and artificial learning to 
automatically identify and map themes and concepts from qualitative data, such as interviews, open-ended surveys, transcriptions of focus groups, or other text-based data. ${ }^{51}$ The Leximancer manual

52 indicates that, Leximancer conducts its analysis in three stages: First stage is concerned with identifying frequently occurring concepts that are weighted term classifiers. These are developed through an interactive process in which Leximancer applies Bayesian philosophies. According to Smith and Humphreys ${ }^{51}$ Bayesian decision theory, takes into consideration how often two words co-occur as well as how frequently they occur together, but also how often they occur apart; this is similar to a log odds, or two-way contingency statistics. Smith and Humphreys further suggest that this metric gives a tighter binding of relevant terms to concepts that are suitable for extracting discriminating attributes of entities or concepts. The use of Bayesian theory has been utilised previously by Marrone, Nardone 53 for evaluating the vulnerabilities of critical infrastructure assets.

In the second stage, Leximancer utilises Bayesian approach to analyses the word frequency and concepts' co-occurrence where data to identify families of terms that tend to be used together in the text. $^{54}$ This results in an asymmetric cooccurrence matrix. ${ }^{55}$ In the final stage of the analysis, Leximancer Analysis derives themes by allocating concepts around a highly connected concept in respectively area. The Leximancer manual further specifies that the more themes overlap, the more interconnectedness there is. ${ }^{52}$ Leximancer analysis software package program has been used by a broad range of fields where number of rigorous studies from a broad range of fields including: humanities, social sciences and medical/health sciences have validated Leximancer by comparing stability, reproducibility, and correlative and functional tests. ${ }^{51,54,55}$

For the purpose of this examination, Thematic and concept maps were created for both the official reports and the academic literature pertaining to the nuclear disaster event. These maps provided additional details on the conceptual nature of the role of management in these disasters. In the process of analysis, the authors merged most singular and plural words along with words that had the same meaning. For example, the words "asset" and "assets", "skill" and "skills", "employees” and "employee” were merged because they were closely connected and located in the semantic space. The author also removed general terms such as: "including”, “use”, “including”, "needs”, “example”, “million” "provides”, "existing”, “appropriate" that did not provide meaning to the concept maps. The analysis output (Theme 50\%, Concept $100 \%$ ) was used to visualize all the thematic maps for consistency. This is in line with the process outlined in Leximancer manual and other previous published works. ${ }^{51,52,55}$

\subsection{Results and discussion}

This paper examines the key role played by management prior to during and after the three nuclear disaster identified. The findings identify four different theme categories. The categories are based on the connectivity value (\%). These categories are: most important theme (75\%-100\%), important theme $(50 \%-74 \%)$, moderately important theme (25\%-49\%), and the less important theme $(1 \%-24 \%)$. Findings from the qualitative analysis for the two different literature sets into the disasters are outlined as follows.

\subsection{Nuclear Disaster Official Reports}

Figure 1 presents the themes and concepts for the nuclear disaster official reports. The most important theme accidents (100\%), which is closely related to concepts such as "accident”, “nuclear”, "safety”, "plant”, “power” and "government”. The moderately important theme to emerge was "management" (50\%) (Not in line with your defined ranges- most important theme (75\%$100 \%)$, important theme (50\%-74\%), moderately important theme (25\%-49\%), and the less important theme (1\%-24\%) where there were close links to "disaster", "systems", "report", "investigations” and finally "processes”. The next moderate theme with inside the official report was employee ( $37 \%$ ) where close links to "operating”, "results”, “design”, “analysis" and "result” was displayed. The lesser important themes identified were radiation issues (25\%), regulator (23\%), and safety (20\%). One interpretation is that t combined impact of management, employees focused on safety are the emerging themes overlapping with of the theme of accidents.

Overall the analysis of the official reports into the nuclear sector crisis and disaster events finds that the role of management was a moderately important theme as the major theme was on the "accidents" itself \%) (ensure in line with your defined ranges- most important theme (75\%$100 \%)$, important theme (50\%-74\%), moderately important theme $(25 \%-49 \%)$, and the less important theme (1\%-24\%). However, management had close links to systems and to the disasters itself as there was a direct pathway between these concepts. 


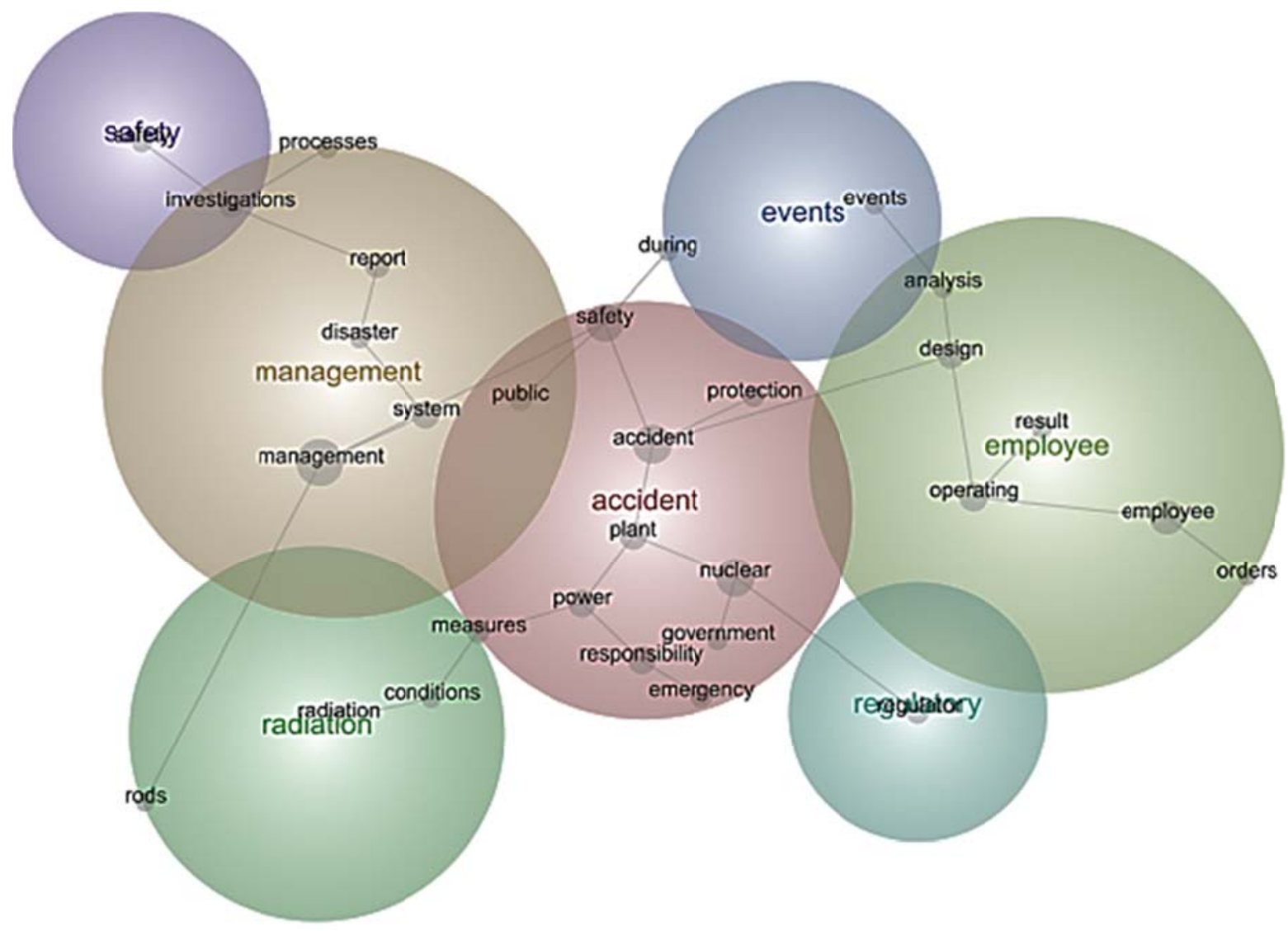

Figure 1: Thematic and Conceptual Map on Nuclear Disaster Official Reports (source 46-50)

According to Leximancer themes, management had a direct impact on the number and impact of disasters and other safety outcomes. Further, the enforcement of safety rules and monitoring and enforcement of the management role in relation to monitoring and enforcement was not sufficient. It was highlighted in the reports that the disasters were caused by a combination of personnel error, design deficiencies, and component failures. The recommendation of the reports for organisations and regulatory bodies is to improve their training and development is the first step to building a more safety-conscious organizational culture. While safety was identified, the issues of organisational culture did not arise as a theme on its own or as a issue then examining the analysis of nuclear disaster official reports however, further review of these reports find that organisational culture and safety culture issues are important to ensure safety outcomes.
The official report by The President's Commission on the Accident at Three Mile Island nuclear plant found that "The accident at Three Mile Island (TMI) occurred as a result of a series of human, institutional, and mechanical failures."46, p. 27 The report went onto say that both management and engineering personnel also had difficulty in analyzing events. It seems that the managers were unprepared for the significant amount of hydrogen generated during the accident and despite supervisory personnel taking charge there was “... significant delays occurred before core damage was fully recognized, and stable cooling of the core was achieved." 46, p. 29 Further analysis of this report found that there was no reference to organisational culture, safety culture, safety climate. Similarly, a report in 2012 by the U.S. Nuclear Regulatory Commission $^{48}$ into the Three Mile Island nuclear disaster identified 12 major changes which have occurred since the accident. Whilst discussing things like plant safety, revamping operator 
training and staffing requirements, improved instrumentation and controls for operating the plant there was once again no mention of culture issues but then again, it could be argued that they both did infer or present some limited discussion about the role of a competent safety culture in ensuring safety outcomes for the organization.

Further examination into the International Atomic Energy Agency in 1992 report into the Chernobyl reactor explosion finds that they concluded that there the culture was poorly prepared and trained to respond to the accident. The disaster was

improved operator training; and the importance of the man-machine interface."49, p.6 This could indicate that the report somewhat acknowledged) the importance of management in developing a competent culture of safety Despite these ongoing disasters it appears that the lessons about the importance of management issues identified from Three Mile Island and Chernobyl disasters appears to have been overlooked by management of Tepco, the operation of the Fukushima Nuclear power plant. Whilst the official report of The Fukushima Nuclear Accident by Independent Investigation Commission acknowledged that the tsunami played a role in the destruction of the diesel generators responsible for supplying cooling water to the reactor, it was in fact a man-made disaster as the report highlighted major management failures.

They further found that there was collusion between the government, the regulators and Tokyo Electric Power Company, and the lack of governance by said parties. $^{50}$ The commission stated that "We believe that the root causes were the organizational and regulatory systems that supported faulty rationales for decisions and actions, rather than issues relating to the competency of any specific individual."50 p. ${ }^{16}$ While further finding that "the company was found to be lacking the self-governance competence to set adequate measures for the prevention of accidents, and the culture to make concerted efforts to improve nuclear safety from the people's point of view." 50, p.75 organisational culture was only referred on four occasions and safety culture only four as well. The issues of management in the report was mainly focused on crisis management attributed to engineers conducting a safety experiment and not following correct procedures and not adhering to various policies. ${ }^{17,}{ }^{49}$ The report further found that the accident was accompanied by major communications problems, inappropriate policies and procedures that led to conflicting information. The report further went onto say that "The accident at Chernobyl demonstrated that the lessons from the Three Mile Island accident had not been acted upon in the USSR: in particular, the importance of systematic evaluation of operating experience; the need to strengthen the on-site technical and management capability, including

and not on managing the employee for mitigation and or prevention efforts, in fact mitigation management practices or efforts was not mention at all, and risk management was mention once.

\subsection{Nuclear Disaster Academic literature}

The analysis of the literature data set for the academic literature on the three nuclear disasters identifies a number of themes and concepts, as shown in Figure 2. The most important theme is management $(100 \%)$ where the concepts of "management", "systems", “operation”, and "employee" were the top four concepts. Organisation (50\%) was the next major theme to emerge and were there were four concepts “organisation”, “crisis”, "possible” (risk of crisis developing), and "research". Moderately important theme were industry (44\%) and information (28\%) with results $(8 \%)$, government $(7 \%)$ been the lesser important themes.

The analysis of the literature data set for the academic literature on the three nuclear disasters identifies a number of themes and concepts, as shown in Figure 2. The most important theme is management (100\%) where the concepts of "management”, “systems”, “operation”, and "employee" were the top four concepts. Organisation (50\%) was the next major theme to emerge and were there were four concepts "organisation”, “crisis”, "possible” (risk of crisis developing), and "research". Moderately important theme were industry (44\%) and information (28\%) with results $(8 \%)$, government $(7 \%)$ been the lesser important themes. 


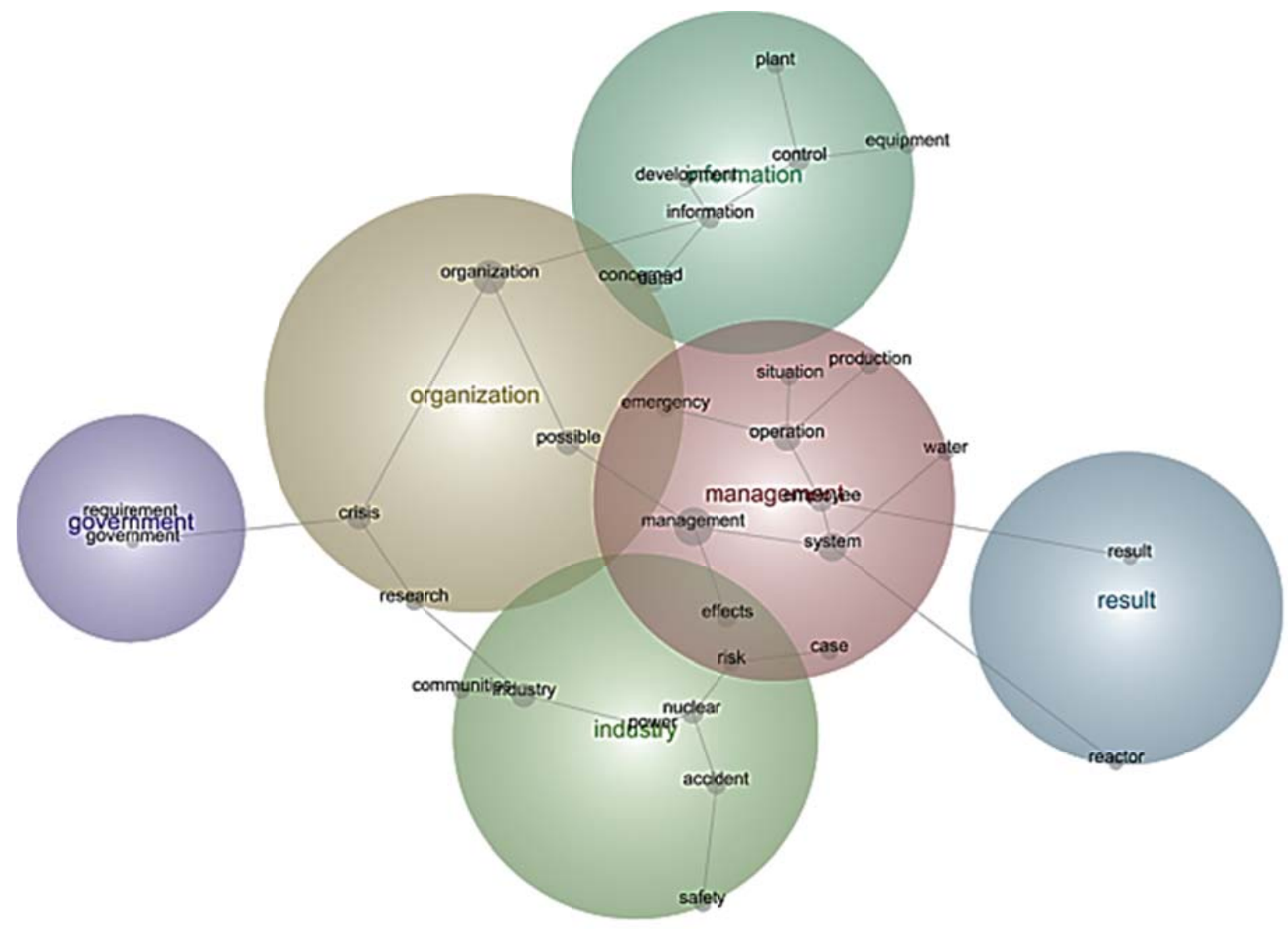

Figure 2: Thematic and Conceptual Map Analysis from Nuclear Disaster Academic literature N=95

Unlike the official reports into the nuclear disasters, "management" was the major theme for the academic literature where management had proximity and overlap with three other themes namely organisation, information, and industry. Despite the overlap, there appears to be a gap in the literature about the role of management in shaping an effective organisational culture. According to the analysis, management has a direct role in the organisational and crisis post disaster event and not on the pre phases of the crisis and disaster cycle moreover. This is not possible. There can be no "post" unless there is a "pre", hence there is a role of management in ensuring crisis management from the development to the implementation phase. new information is required about the efficiency of new policies, processes and procedures for ensuring safety outcomes. It was further highlighted that management was responsible for the development of reporting systems for the organisation to regulatory bodies about crisis management - especially in relation to systems operations and e risk management of the accidents .
While the analysis of the academic literature did not identify organisation and safety cultural issues it should be noted that a number of authors have suggested that these are very important factors in managing or preventing a disaster. Hollnagel and Fujita $^{56}$ in their investigation into the Fukushima nuclear disaster identified from a resilience engineering perspective that organisational culture was important - especially The Institute of Nuclear Power Operations ${ }^{57}$ developed a dedicated document on the importance of strong nuclear safety culture where they viewed safety culture is an essential attributes of a healthy safe nuclear facility. Overall the academic literature into Nuclear Disaster appears to investigate the role of management inside and across the disaster situation compared to that of official enquiries or reports; however, there is a clear theme about the role of management and the need to engage employees so as to form a competent organisational and safety culture, and mitigation management approaches. 
Table 1. Comparison of top 7 key concepts of crisis-disaster derived from Leximancer analysis

\begin{tabular}{|c|c|c|}
\hline Concepts & $\begin{array}{c}\text { Nuclear Disaster Official } \\
\text { Reports }\end{array}$ & $\begin{array}{c}\text { Nuclear Disaster Academic } \\
\text { Literature }\end{array}$ \\
\hline Management & $*$ & $\nLeftarrow$ \\
\hline Safety & $\nLeftarrow$ & $\nLeftarrow$ \\
\hline Crisis/disaster/accident & $*$ & $*$ \\
\hline System/process/reports & $\nLeftarrow$ & $\nLeftarrow$ \\
\hline Organisation/Company & & $\nLeftarrow$ \\
\hline Human error & & 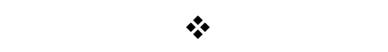 \\
\hline Employees/people/personnel & $*$ & \\
\hline
\end{tabular}

\subsection{Comparing the Academic literature and the official reports}

The Leximancer manual ${ }^{52}$ indicates that the more themes overlap, the more interconnectedness there is. In this regard, the themes emerging from the Nuclear Disaster Academic literature are Management, safety, System/process/reports and, Crisis/disaster/accident (see table 1). Human error was not identified as a major theme by the Nuclear Disaster Official Reports but, the academic literature did. Further examination of the Nuclear Disaster Official Reports did identify the importance of human errors in causing the disaster.

Surprisingly neither the academic literature nor the official reports highlighted the importance of employee competence on disaster outcomes. Similarly, very little has been written about the role and importance of "government/authority" acting as a regulatory authority in responding to disasters. Both the academic and official reports have overlooked the importance of organisational culture, safety culture, and competent well trained employees in a crisis and disaster event. Consequently, there appears to be a gap in the literature about the importance of an competent safety and organisational culture in ensuring safety outcomes especially during crisis and disaster events. In general nuclear disaster official reports had a greater focus on the accident or the post disaster itself whereas the academic literature had a greater focus on the role of management. Both fail to investigate the role of organisational culture, safety culture and the importance of management in shaping employees to develop effective precrisis processes.

\subsection{Conclusion}

While there are some similarities between both the academic literature and official reports into the nuclear disasters, both have overlooked the issues of organisational culture, safety culture, preparedness and mitigation disaster management activities. The overall analysis of the information presented is that management plays a major role in shaping employees' responses to a crisis and disaster event. More importantly the academic literature and management of EAMO needs to develop a better understanding of good crisis/disaster management practice that are conducive to ensure effective crisis and disaster mitigation management. 


\section{References}

1. Amadi-Echendu, J., et al., What is Engineering Asset Management?, in 2nd World Congress on Engineering Asset Management and the 4th International Conference on Condition Monitoring, Harrogate: United Kingdom. 2007 pp. 116-129.

2. Pearson, C.M. and I.I. Mitroff, From crisis prone to crisis prepared: A framework for crisis management. The Executive, 1993. Vol. 7 no.1: pp. 4848.

3. Mitroff, I.I., Think like a sociopath, act like a saint. Journal of business strategy. Vol. 25 no. 52004 , pp. 42-53.

4. Mitroff, I.I., Knowing: how we know is as important as what we know. Journal of Business Strategy, Vol 29, no. 3, 2008, pp. 13-22.

5. Stoop, J. and S. Dekker, Are safety investigations pro-active? Safety Science, Vol 50, no. 6 2012, pp. 1422-1430.

6. Jaques, T., Issue management and crisis management: An integrated, non-linear, relational construct. Public Relations Review, Vol. 33, no. 2, 2007pp. 147-157.

$7 . \quad$ Verbano, C. and F. Turra, A human factors and reliability approach to clinical risk management: Evidence from Italian cases. Safety Science, Vol. 48, no. 5, 2010, pp. 625-639.

$8 . \quad$ Gould, K.S., A.J. Ringstad, and K.v.d. Merwe. Human Reliability Analysis in Major Accident Risk Analyses in the Norwegian Petroleum Industry. in Proceedings of the human factors and ergonomics society 56th annual meeting. 2012.

9. Pang, A. and S.L. Yeo, Examining the expertise, experience, and expedience of crisis consultants in Singapore. Public Relations Review, Vol. 38, no. 5, 2012, pp. 853-864.

10. Mitroff, I.I., P. Shriwastava, and F.E. Udwadia, Effective Crisis Management. Academy of Management Executive, Vol. 1, no. 4, 1987, pp. 283-292.

11. Faulkner, B., Towards a framework for tourism disaster management. Tourism Management, Vol. 22, no. 2, 2001, pp. 135-147.

12. Baker, J.A., et al., The B.P. U.S. Refineries Independent Safety Review Panel. 2007, Washington.

13. Bozeman, B., The 2010 BP Gulf of Mexico oil spill: Implications for theory of organizational disaster. Technology in Society, Vol. 33, no. (3-4), 2011 pp. 244252.

14. Skogdalen, J.E. and J.E. Vinnem, Quantitative risk analysis of oil and gas drilling, using Deepwater Horizon as case study. Reliability Engineering \& System Safety, Vol. 100, no. 1, 2012, pp. 58-66.

15. Hirschberg, S., G. Spiekerman, and R. Dones, Severe Accidents in the Energy Sector, in PSI Report. 1998: Villigen, Switzerland.

16. Hirschberg, S., et al., Severe accidents in the energy sector: comparative perspective. Journal of Hazardous Materials, Vol. 111, no. 1-3, 2004, pp. 5765.

17. Sovacool, B.K., The costs of failure: A preliminary assessment of major energy accidents, 19072007. Energy Policy, Vol. 36, no. 5, 2008, pp. 18021820.

18. Ladd, A.E., Pandora's Well: Hubris, Deregulation, Fossil Fuels, and the BP Oil Disaster in the Gulf. American Behavioral Scientist, Vol. 56, no. 1, 2012, pp. 104-127.

19. Graham, B., et al., Deep Water: The Gulf Oil Disaster and the Future of Offshore Drilling, National Commission on the BP Deepwater Horizon Oil Spill and Offshore Drilling: Washington D.C. 2011, pp. 1-382.

20. Zuashkiani, A., H. Rahmandad, and A.K.S. Jardine, Mapping the dynamics of overall equipment effectiveness to enhance asset management practices. Journal of Quality in Maintenance Engineering, Vol. 17, no. 1, 2011, pp. 74-9.

21. Felder, F.A., A critical assessment of energy accident studies. Energy Policy,Vol. 37, no. 12, 2009 pp. 5744-5751.

22. Burgherr, P., P. Eckle, and S. Hirschberg, Comparative assessment of severe accident risks in the coal, oil and natural gas chains. Reliability Engineering \&amp; System Safety,Vol. 105, 2012, pp. 97-103.

23. Aoki, M. and G. Rothwell, A comparative institutional analysis of the Fukushima nuclear disaster: Lessons and policy implications. Energy Policy, Vol. 53, 2013, pp. 240-247.

24. Yukl, G., Leadership in organisations,. 8th ed. 2012, Essex: Pearson.

25. Wood, J., et al., Organisational Behaviour: Core concepts and application. 2nd ed. 2011, Milton: John Wiley \& Sons.

26. Muchiri, M.K., Leadership in context: A review and research agenda for sub-Saharan Africa. Journal of Occupational and Organizational Psychology, Vol. 84, 2011, pp. 440-452.

27. Novak, J.P., Exploring Training and Development in Queensland SME Training and Development Innovators, in Faculty of business and Law. 2012, University of southern Queensland: Toowoomba. pp. 236.

28. Wiesner, R. and P. Innes, In Search of Tallent: The Link between Recruitment Configuration and SME Firm Performance. International Journal of Human Resource Management. Currently under review, 2010.

29. Schermerhorn, J., et al., Management Foundations and Applications. 1st Asia-Pacific ed. 2011, Milton: John Wiley \& Sons.

30. Samson, D. and R.L. Daft, Fundamentals of Management. 3rd ed. 2009, Orlando: Dryden Press.

31. Bass, B.M., Transformational Leadership: Industrial, Military, and Educational Impact. 1998, Mahwah, NJ: Lawrence Erlbaum Associates.

32. Brunetto, Y. and M. Xerri, Ensuring the implementation of engineering asset management: understanding organisational culture', paper presented to WCEAM 2011, in Sixth World Congress on Engineering Asset Management. 2011: Cincinnati, Ohio, USA.

33. Lloyd, C., Asset Management: Whole-Life Management Of Physical Assets. 2010, London: Thomas Telford Ltd.

34. Boin, A. and A. McConnell, Preparing for Critical Infrastructure Breakdowns: The Limits of Crisis Management and the Need for Resilience. Journal of Contingencies and Crisis Management, Vol. 15, no. 1, 2007, pp. 50-59.

35. Salaman, G., J. Storey, and J. Billsberry, eds. Strategic human resource management: theory and practice. 2nd ed. 2005, SAGE Publications: London.

36. Hagen, A., I. Udeh, and M. Wilkie, The Way That Companies Should Manage Their Human 
Resources As Their Most Important Asset: Empirical Investigation. Journal Of Business And Economics Research,Vol. 1, no. 1, 2011, pp. 81-92.

37. Bass, B.M. and B.J. Avolio, Transformational leadership and organizational culture. Public Administration Quarterly, Vol. 17, 1993, pp. 112-22.

38. Farr-Wharton, R. and Y. Brunetto, Female entrepreneurs as managers. Gender in Management: An International Journal, Vol. 24, no. 1, 2009, pp. 14-31.

39. Davies, H. and M. Walters, Do all crises have to become disasters? Risk and risk mitigation. Disaster Prevention and Management, Vol. 7, no. 5, 1998, pp. 396-400.

40. Hartnell, C.A., A.Y. Ou, and A. Kinicki, Organizational Culture and Organizational Effectiveness: A Meta-Analytic Investigation of the Competing Values Framework's Theoretical Suppositions. Journal of Applied Psychology, Vol. 96, no. 4, 2011, pp. 677-694.

41. Hofstede, G., Cultural contraints in management theories. Academy of Management Executive, Vol. 7, no. 1, 1993, pp. 81-94.

42. Deshpande', R. and J. Farley, Organizational culture, market orientation, innovativeness, and firm performance: an international research odyssey. International Journal of Research, Vol. 21, no. 1, 2004 , pp. 3-22.

43. Boisnier, A. and J.A. Chatman, The Role of Subcultures in Agile Organizations, in Leading and managing people in dynamic organizations, R.S. Petersen and E.A. Mannix, Editors. 2003, Erlbaum Associations: Lawrence.

44. Bosher, L., et al., Built-in resilience to disasters: a pre-emptive approach. Engineering, Construction and Architectural Management, Vol. 14, no. 5, 2007, pp. 434-446.

45. El-Baz, H.S. and S.M. El-Sayegh, Competency Domain Model and the Perception of Engineering Managers in the United Arab Emirates. Engineering Management Journal, Vol. 22, no. 1, 2010, pp. 3-12.

46. Kemeny, J.G., et al., Report of The President's Commission on The Accident at Three Mile Island. 1979, The White House: Washington. pp. 1-179.

47. Nuclear Safety Analysis Center, Analysis of Three Mile Island - Unit 2 Accident 1980: California pp. $1-531$.

48. U.S. Nuclear Regulatory Commission, Three Mile Island Accident. 2012.

49. International Atomic Energy Agency, The Chernobyl accident: updating of INSAG-1: A report by the International Nuclear Safety Advisory Group. 1992: VIENNA. pp. 1-148.

50. Kurokawa, K., et al., The official report of The Fukushima Nuclear Accident Independent Investigation Commission. 2012, The National Diet of Japan (NAIIC): Tokyo. pp. 1-86.

51. Smith, A. and M. Humphreys, Evaluation of unsupervised semantic mapping of natural language with Leximancer concept mapping. Behaviour Research Methods, Vol. 1, no. 38, 2006, pp. 262-279.

52. Leximancer, Leximancer Manual. 2011, Leximancer: Brisbane. pp. 1-176.

53. Marrone, S., et al., Vulnerability modeling and analysis for critical infrastructure protection applications. International Journal of Critical Infrastructure Protection, Vol. 6, no. 3-4, 2013, pp. 217227.
54. Cretchley, J., D. Rooney, and C. Gallois, Mapping a 40-Year History With Leximancer: Themes and Concepts in the Journal of Cross-Cultural Psychology. International Association for Cross-Cultural Psychology, Vol. 41, no. 3, 2010, pp. 318-328.

55. Fruhen, L.S., et al., From the surface to the underlying meaning-an analysis of senior managers'safety culture perceptions. Safety Science, Vol. 57, no. 1, 2013, pp. 326-334.

56. Hollnagel, E. and Y. Fujita, The Fukushima disaster - systemic failures as the lack of resilience. Nuclear engineering and technology, Vol. 45, no. 1, 2013, pp. 2013.

57. Institute of Nuclear Power Operations, Principles for a Strong Nuclear Safety Culture 2004, Atlanta: Institute of Nuclear Power Operations. 